\title{
Limitations of High-Voltage Insulation
}

$\mathrm{D}^{\mathrm{n}}$ R. WHITEHEAD, of Johns Hopkins University, communicates an interesting paper to the Journal of the Franklin Institute of September on the limitations of high voltage. Fifty years ago, it was thought that electrical transmission distances in America would never go much beyond 150 miles and that the economical voltage would not rise much above 110 kilovolts. The grounds for this opinion seem to have been that the distances between avail. able sources of power, whether hydraulic or steam, were never greater than about 300 miles. At the present time, there are not many transmission systems for distances greater than 150 miles, but there are several working at 220 kilovolts. A conspicuous example is the Boulder Dam-Los Angeles transmission line over a distance of 300 miles at 287 kilovolts.

Calculation has shown the economic advantage of power development and transmission to greater distance at a higher voltage. Dr. Whitehead discusses the limitations placed on a further increase of trans. mission voltage by the insulating properties of the materials which are at present available. Those most commonly used are the atmospheric air, ceramic materials such as glass and porcelain, petroleum oils and various composite fibrous materials such as impregnated paper. The important electrical properties of the materials used for the insulation of high-voltage circuits are conductivity and electric strength. The conductivity measures the ability of the material to withstand slow leakage, and the electric strength measures its ability to withstand breakdown or actual failure and short circuit. All materials, including liquids and gases, have some electrical conductivity, but they vary over a very wide range, the conductivity of copper being $10^{20}$ times greater than that of a good mineral oil. Those with high insulating properties may vary a million times between themselves, but they are all classified as available for high-voltage insulation.

All the materials used for insulating high voltage must have high electric strength. Usually the over- head high-voltage transmission line depends on the atmospheric air for its insulation. The conductivity of the air is so small initially that it can be neglected. As there are always a few ions present, they move backwards and forwards under the forces exerted by alternating high voltage, and when they move fast enough they have collisions with neutral ions, thus creating new ions and increasing the conductivity of the air between the lines. This causes the well. known corona or brush discharge surrounding the conductors. The discharge increases the conductivity and energy loss in the air and is thus a limitation to its insulating properties. Up to the present, it has been found possible-notwithstanding the great increases in voltage values-by separating the conductors sufficiently and increasing their diameter, to prevent coronas from forming. In the Boulder Dam line the main conductors are hollow and $1 \cdot 4$ inch in diameter; they work at $285 \mathrm{kv}$. To get a corona the voltage would have to be increased to $450 \mathrm{kv}$.

It appears that the saving effected in conducting material at higher transmission voltages is partly offset by the increased cost of the insulation. The higher the voltage the greater the cost of the insulation and the construction of the line, as the minimum total cost must always determine the most economical value of voltage. We have reached a stage in raising voltage values where the physical dimensions of the line are so great as to be practically prohibitive. To meet these limitations, special forms of construction of the conductor system and special auxiliaries to the insulation system have become necessary, and these impose further limitations to increasing the voltage.

For these reasons, engineers are studying the use of underground cables for high voltages. There are now several installations at $132 \mathrm{kv}$. and a few at $220 \mathrm{kv}$. Some of these systems using 'oil-filled' cables have given satisfaction for more than seven years, and credit is due to the engineers in the experimental laboratories where they were developed.

\section{Building Research*}

\begin{abstract}
A SPECTAL feature of the report of the Building A Research Board for the year 1936 is the retrospect prepared by the Director, Dr. R. E. Stradling, reviewing the progress made during the eleven years since the Station was established in its present laboratory at Garston, Herts. For four years previously the organization was taking shape, and the value of the experience then gained may be judged from the progress made since 1925. The work of the Station goes ahead continuously and, in knowledge of materials and methods and in experience, considerable progress has been made, but it is seldom possible in any one year to chronicle any

* Department of Scientific and Industrial Research. Report of the Building Research Board, with a Report of the Director of Building Research for the Year 1936. Pp. vi $+210+25$ plates. (London. R.M. Stationery Office, 1937). 48. net.
H.M.
\end{abstract}

definite advance. Over the longer period the work can be seen in better perspective, the import of it becomes more evident and lines of future develop. ment are more clearly indicated.

For example, the Library begun primarily for internal service with a stock of two thousand items, has increased fully tenfold in size and has become a focal point for world-wide information regarding all matters appertaining to building. Its functions are not merely to stock all this material, but also to include its study and documentation for the promotion of research and assistance in inquiries. The fact that this work of the Library, its resources, and the kind of service it can provide are insufficiently well known outside, justifies special mention of them in detail, for, as the Director notes, there is no reason why 